\section{Arabic expression of emotion}

SIR: Okasha et al (BJP, June 94, 164, 818-825) claim that "Arab patients do not usually have complaints of depressive, anxiety or panic symptoms directly". This is untrue, as the Arabic language contains very rich expressions of such emotions. Kaaba, or depression, is in everyday use. Indeed, the numerous psychological symptoms of depression and anxiety - Kalk - can be given by any Arab patient. Sorrow, sadness, fear, apprehension, irritation, discontent with oneself and others, misanthropy, love of seclusion, and loss of interest in everything is Mafish Mazag. Some of the Egyptian songs show how excessive love (Walu, Hob) leads a person to crying and depression.

Many medieval Arabic physicians, including AlMajusi, Ishaq Ibn Imran, Ibn Sina and Ar-Razi, described melancholia (Rosenthal, 1978). Ar-Razi called melancholia Al WasWas As-Sawdawi, the black obsession. Even somatisation was described as a type of depression originating in the epigastrium, and was known in Arabic as Muraqiya, or hypochondric melancholia.

Arab patients know what depression means from the teaching of the Koran, which expresses this emotion in many verses; to cite just one, in Surrah XII, Jacob, after the loss of his son, Joseph, says, "Alas, my grief for Joseph! and his eyes were whitened with sorrow that he was suppressing. $\mathrm{He}$ said: I expose my distress and anguish only onto Allah and I know from Allah that which ye know not".

Rosenthal, F. (1978) Ar-Razi on the hidden illness. Bulletin of the History of Medicine, 52, 45-60.

HANAFY YousSEF,

St Davnet's Hospital,

Monaghan,

Ireland

\section{Clozapine-induced neutropenia, or not}

SIR: Beer et al (BJP, June 1994, 164, 850) suggest that the Clozaril Patient Monitoring Service (CPMS) is being unduly vigilant by stopping a patient's clozapine on the basis of a single abnormally low white blood cell or neutrophil count ('a red alert').

The mortality rate of agranulocytosis can be as high as $35 \%$ (Gerson et al, 1994). Monitoring of all the 6122 patients exposed to clozapine in the UK has shown the incidence of neutropenia to be $3.6 \%$ and agranulocytosis to be $0.75 \%$. The fact that only two patients with agranulocytosis failed to recover
(4.3\% mortality rate), in one of whom the white blood count had already begun to rise before the patient died, is testimony to the performance of the CPMS. The monitoring system was set up to minimise the incidence of fatal agranulocytosis by early detection of neutropenia, thereby enabling prompt discontinuation of the causative drug.

We are acutely aware of the effects that stopping clozapine may have on the lives of the previously treatment-resistant schizophrenics who respond to therapy; up to two-thirds of this group of severely ill patients will improve greatly with clozapine. The decision to stop clozapine is taken on the grounds of patients safety, and is never taken lightly.

The decision to stop treatment after a single 'red alert' is not taken by looking at the result in isolation, but as part of any downward trend in the white cell and neutrophil counts, the duration of clozapine treatment, the patient's age, sex and baseline haematological profile. Factors such as margination are also considered.

The exact cause of agranulocytosis is unknown; it may be via an immune-mediated or toxic mechanism (Saffermann et al, 1992; Veys et al, 1992). Evidence to support an immune-mediated phenomenon comes from nine patients rechallenged with clozapine in the USA after they had recovered from a leucopenic reaction (white cell count $<3 \times 10^{9} /$ ) or agranulocytosis. Leucopenia or agranulocytosis was faster the second time and occurred in all nine cases. For this reason, CPMS believes that based on present evidence the risk to a patient is too great for clozapine rechallenge; therefore, it is only in cases where the 'red alert' is thought not to be related to clozapine that therapy can recommence. Each red alert is carefully reviewed by the CPMS and an independent second opinion from an experienced consultant haematologist is sought for cases where there is doubt as to whether clozapine was a causate. Indeed, there have been patients for whom a single red alert have been judged following this expert advice not to be related to clozapine, and treatment has then been resumed with continued careful monitoring.

It is often noted that there is a temporary increase in neutrophil levels shortly after a red alert. This probably represents a physiological response to the neutropenia, as immature neutrophils are pushed out from the bone marrow by a feedback mechanism. The same phenomenon has also been seen in several patients before agranulocytosis. We are therefore cautious about the significance of this temporary increase in white cells, and choose not to use two consecutive red alerts as a flag for stopping clozapine patients for this reason. 